\title{
THE INDEX OF HARM: A MEASURE FOR COMPARING OCCUPATIONAL RISK ACROSS INDUSTRIES
}

\author{
KENNETH A. SOLOMON, STANLEY C. ABRAHAM
}

R-2409-RC

JUNE 1979 


\section{DISCLAIMER}

This report was prepared as an account of work sponsored by an agency of the United States Government. Neither the United States Government nor any agency Thereof, nor any of their employees, makes any warranty, express or implied, or assumes any legal liability or responsibility for the accuracy, completeness, or usefulness of any information, apparatus, product, or process disclosed, or represents that its use would not infringe privately owned rights. Reference herein to any specific commercial product, process, or service by trade name, trademark, manufacturer, or otherwise does not necessarily constitute or imply its endorsement, recommendation, or favoring by the United States Government or any agency thereof. The views and opinions of authors expressed herein do not necessarily state or reflect those of the United States Government or any agency thereof. 


\section{DISCLAIMER}

Portions of this document may be illegible in electronic image products. Images are produced from the best available original document. 


\section{PREFACE}

This report extends a methodology first proposed by the International Commission on Radiological Protection for use in comparing occupational risks among workers exposed to radiological and nonradiological hazards, or "harms." This new index-of-harm methodology should prove useful in comparing occupational risks among industries and in quantifying the benefits of reducing occupational (and possibly generalpopulation) risks. Several avenues of research are suggested which would permit a more realistic quantification of occupational and generalpopulation risks.

The report is addressed to policymakers and others interested in regulating risk. It provides an alternative decision technique for formulating policies for assessing and reducing risk, as well as for regulating the environment, health, and safety across all industries. Preparation of the report was supported in part by The Rand Corporation through its own research funds. 

This report explores the implications of an index-of-harm methodology that compares occupational risk among workers exposed to radiological and nonradiological harms. It extends the work of the International Commission on Radiological Protection (ICRP) by considering American rather than European and Japanese industry groups, by treating the relative importance of various occupational harms as a parameter rather than an arbitrary constant, and by identifying several ways in which both the methodology and the data base could be improved. Unfortunately, the data base is too fragmented, and radiological risk estimates are too imprecise for quantitative comparisons across industries. Our inclusion of subjective risk preferences is one way to make policy-relevant judgments based on a limited data base.

To illustrate the use of the methodology, we examined in a cursory way the risk effects of six occupational harms--three nonradiological (death, accidental injury, and disease or illness) and three radiological (radiation-induced somatic effects, genetic effects, and somatic effects to the fetus or embryo of pregnant women). A principal difference between the nonradiological and radiological harms is that we have only fragmentary data on the immediate effects of the nonradiological harms and only rough estimates of the delayed effects of the radiological harms. Using the standard eight industry classifications we were able to estimate indexes of harm by industry assuming all workers to be exposed to the three nonradiological harms. Against those indexes, we compared another set we developed from theoretical ICRP projections of occupational workers exposed to the three radiological harms, and with differing average doses of radiation ranging from 0.1 to $5.0 \mathrm{Rem} / \mathrm{yr}$. To take into account controversies surrounding the estimates relating low-level radiological dose to ensuing harm, we have varied the ICRP dose/risk parameter by factors of 0.5 and 5 . In this way, we have bracketed the high and low risk estimates given in the 1972 study by the Committee on Biological Effects of Ionizing Radiation, National Academy of Sciences. 
Our index-of-harm calculations and comparisons were made under five different assumptions about the relative importance or degree of aversion of the six harms in question. Our reference assumption weighted all harms equally; the other assumptions each weighted certain harms, such as radiation-induced genetic damage, more heavily than others. (The particular assumptions chosen are merely illustrative; the formulation of the index allows any assumption about any number of harms to be investigated.)

The results of this analysis show that if we assume the ICRP dose/ risk model is valid, then the lowest index of harm found among the industries examined occurs for radiological workers exposed to the current industry-average leve1 of $0.35 \mathrm{Rem} / \mathrm{yr}$. As the concept of "harm" is both subjective and multidimensional, however, any single index can only partially illuminate its many aspects.

Our study agrees with known accidental fatality rates by showing the riskiest industries to be mining; agriculture, forestry, and fisheries; construction; transportation; and manufacturing--roughly in that order. Using a factor of five times the ICRP dose/risk parameter suggests that the index of harm for radiological workers exposed to 0.35 Rem/yr is still below that of the five riskiest industries. However, the rankings are altered considerably at the regulatory dose level of $5.0 \mathrm{Rem} / \mathrm{yr}$. At that leve1, the nuclear industry would be significantly more risky, particularly when our upper risk estimates are used.

A striking and problematic aspect of this index is that each radiation-induced fatality has roughly half the weight of a corresponding nonnuclear fatality. This is because the average number of years lost per nuclear fatality is assumed to be half that for other industry groups. Thus, death at a later age due to cancer is implicitly viewed as being less "harmful" than an earlier accidental death, because of the fewer years of life lost. Even if the nuclear industry and a comparable nonnuclear industry had the same occupational fatality rate, the nuclear industry would appear to be considerably less "harmful" under assumptions of equal weight. However, our approach to computing an index of harm allows the flexibility of varying the relative importance or "weight" of accidental deaths and radiation-induced fatalities. 
Thus the seriousness of the risk to which workers in radiological occupations are exposed depends in the end on how heavily one fears the onset of radiation-induced cancer or other damage, and hence how heavily one weights the total harm possible from a given low-level radiation dose.

By way of an illustrative example--assessing whether enough is known to lower the maximum radiological exposure dose from 5.0 to 0.5 Rem/yr--the report shows how the index of harm could be used to estimate the amount by which risk may be reduced through the application of this regulatory action. It would then remain to be decided whether those "benefits" were worth the costs of implementing the policy or strategy in question. We thus view the index of harm as a useful tool in quantifying the benefits of reducing occupational (and possibly general-population) risk, and suggest several avenues of research through which both the index and the requisite data base could be improved and made more reliable. 


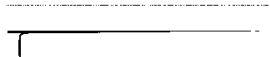




\section{ACKNOWLEDGMENTS}

The authors are especially grateful to Leonard Sagan, M.D., of the Electric Power Research Institute (EPRI) for discussions during the summer of 1978 which stimulated the work described here. They would also like to thank a number of people who reviewed earlier drafts of the report and made helpful written comments: Chris Whipple (EPRI); F. D. Sowby (International Commission on Radiological Protection); Clair C. Palmiter; V. P. Bond (Brookhaven National Laboratory Associated Universities, Inc.); and Rand colleagues J. Aroesty, G. C. Eads, J. Van Ryzin, S. L. Salem, and M. S. Yesley. They also acknowledge the encouragement received from W. S. Baer, D. W. Lyon, and E. C. Gritton of Rand. However, the authors alone are responsible for the contents. 


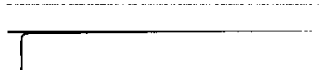




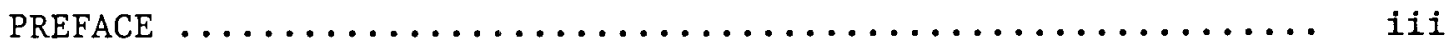

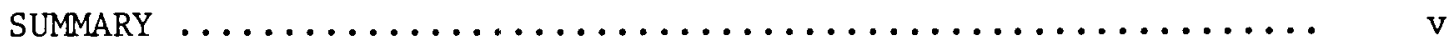

ACKNOWLEDGMENTS $\ldots \ldots \ldots \ldots \ldots \ldots \ldots \ldots \ldots \ldots \ldots \ldots \ldots \ldots \ldots \ldots \ldots \ldots$ ix

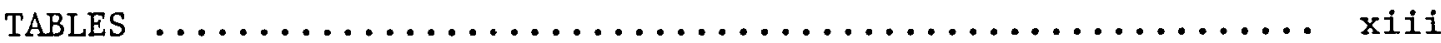

Section

I. INTRODUCTION $\ldots \ldots \ldots \ldots \ldots \ldots \ldots \ldots \ldots \ldots \ldots \ldots \ldots \ldots \ldots \ldots$

II. ESTIMATING AN INDEX OF HARM $\ldots \ldots \ldots \ldots \ldots \ldots \ldots \ldots \ldots \ldots \ldots \ldots \ldots \ldots \ldots \ldots$

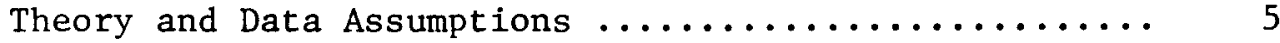

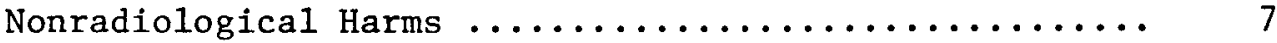

Radiological Harms $\ldots \ldots \ldots \ldots \ldots \ldots \ldots \ldots \ldots \ldots \ldots \ldots . \ldots \ldots$

III. RESULTS AND CONCLUSIONS $\ldots \ldots \ldots \ldots \ldots \ldots \ldots \ldots \ldots \ldots \ldots \ldots$

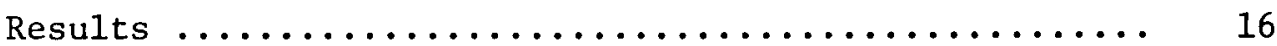

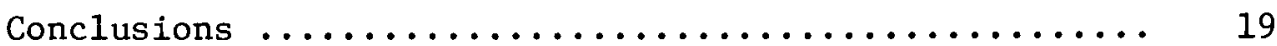

IV. AN ILLUSTRATIVE EXAMPLE $\ldots \ldots \ldots \ldots \ldots \ldots \ldots \ldots \ldots \ldots \ldots \ldots \ldots \ldots \ldots$

V. TOPICS FOR FURTHER RESEARCH $\ldots \ldots \ldots \ldots \ldots \ldots \ldots \ldots \ldots \ldots \ldots, 32$

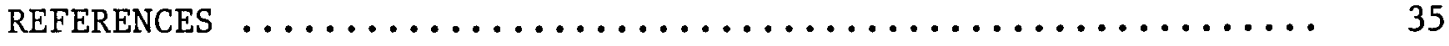


-xiii-

TABLES

1. Types of Harm $\ldots \ldots \ldots \ldots \ldots \ldots \ldots \ldots \ldots \ldots \ldots \ldots \ldots \ldots \ldots, 8$

2. Average Employment by Industry for Calendar Year $1975 \ldots \ldots \ldots$. 8

3. Person-Years Lost Per 100 Person-Years by Nonradiological Industry and Type of Harm, 1972-1975 ............. 9

4. Assumptions and Weights for Each Type of Harm ........... 11

5. Person-Years Lost Per 100 Person-Years by Type of RadiationInduced Effect and Radiation Dose .................. 14

6. Indexes of Harm for Radiological and Nonradiological Industries Under Selected Assumptions .............. 17

7. Indexes of Harm for Nonradiological Industries Compared with Index-of-Harm Ranges for Radiological Industry by Dose Level, Under Equal Weighting Assumption ........ 20

8. Average Individual and Extrapolated Collective Doses for 10CFR Licensees, 1973-1975 ..................... 27

9. Estimate of the Risk Effect of Low-Level Radiation as a Function of Age and Sex of Individuals 
I. INTRODUCTION

The adequate protection of occupational workers--and of the general population-from hazards of all kinds is a matter of considerable concern to the federal government and many public and private organizations, as well as their counterparts in other countries. Many occupational hazards produce indeterminate effects, often disproportionately affecting some groups of individuals more than others. Determining the harm done, if it is possible to do so at all, may require time-consuming and expensive scientific studies and experimentation, without any assurance that the results will be either comprehensive or generally accepted. Moreover, many such investigations cannot be generalized to other populations, hazards, or industries.

Thus it is only slowly that useful, incremental information is added to the general body of knowledge about occupational risk and safety. As more is known and accepted generally, so also are standards and regulations formulated and enacted. As exposure hazards increase and techniques are developed to comply with prevailing standards, those standards then tend to become progressively stricter. It may be fair to describe the present situation as a dynamic balance struck among at least the following forces:

- value judgments about the societal benefits of materials and processes;

- value judgments that stricter standards increase worker and genera1-population safety;

- legal and administrative decisions;

- rising costs of compliance; and

- changing occupational risk and exposure through both inexorable. increases in industrial production and innovative products, materials, and processes.

In past years, most health and safety standards for both generalpopulation and occupational exposure have been formulated and classified 
by industry. Only recently has some thought been given to occupational risk compared across industries. Such a comparison has been attempted in Publication No. 27 of the International Commission on Radiological Protection (ICRP) [1]. By estimating the working time lost per worker per year from a variety of causes (accidents, disease contracted from industrial exposure, or death from occupational causes) the study reduces the harmful effects from different causes in different industries to a common denominator called an Index of Harm, which then facilitates comparisons among industries. But accurate numbers are difficult to obtain, and combining them for the comparisons is difficult to do objectively. The results of that study are generally regarded as no more than indicative of broad differences in risk among industries.

Such an analysis becomes even more complicated when the effects of radiological and nonradiological harms are compared. In addressing this comparison, ICRP Publication No. 27 reviewed the problems in developing its index of harm and pointed out the severe limitations inherent in both the data and the index. The comparison of radiological and nonradiological effects is complicated by the fact that low-leve1 radiological effects consist almost entirely of delayed effects (in the commercial nuclear power industry, for example, exposures intense enough to cause immediate damage are quite rare), while the nonradiological harms consist mainly of immediate effects (precise data for delayed effects, such as cancer from nonradiological carcinogens, are virtually nonexistent because of the inherently long latency period). These effects are not totally separable, unfortunately, since very large radiation doses can lead to immediate health effects, while many nonradiological harms can result in delayed health effects (e.g., asbestosis or cancer from asbestos, pneumoconiosis from coal mining, etc.). Nevertheless, in our opinion, such shortcomings do not negate the concept of using an index of harm to compare occupational risk across industries.

This study in fact extends the methodology, scope of application, and analysis of the ICRP study. Rather than calculate indexes of harm for Japanese and European industry groups, we calculate them for each of the standard eight American industry classifications [2-5]: 


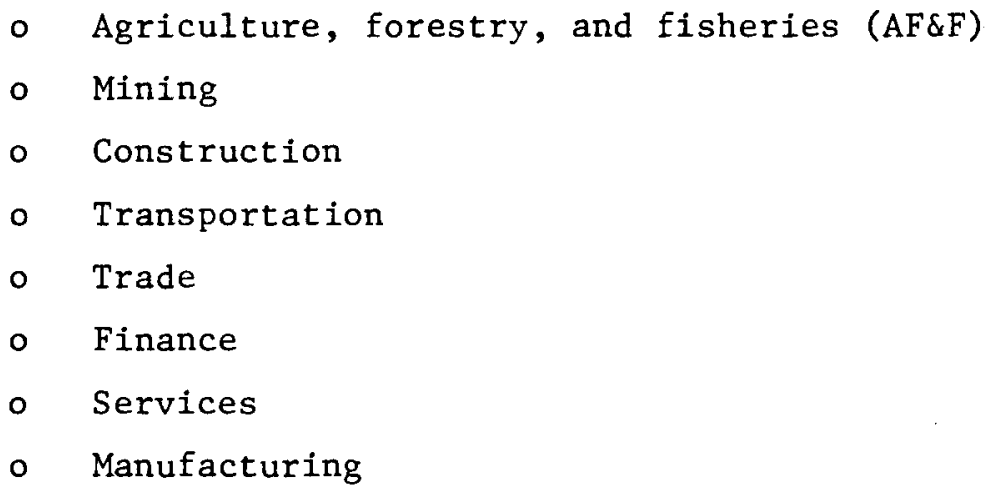

In addition, by combining the radiological portions of each of these industry groupings into a ninth "industry" (i.e., including only those workers in each industry exposed to any degree of radiation) we can calculate indexes of harm for the "radiological" industry for comparison.

The difficulties in estimating radiological risks to health are now widely appreciated. The conversion of this risk to years of lifeshortening requires further calculations based on actuarial life tables, and an appropriate occupational-age distribution. We have not made these calculations, but have relied on the rough estimates given in ICRP27 that each premature cancer and leukemia death due to radiation results in 15 years of life-shortening. Other published estimates, based on more detailed calculations, suggest that the range of average life-shortening is between 13 and 25 years, depending on the age distribution of nuclear workers. Surprisingly, specific data on lifeshortening due to fatalities are not readily available for nonnuclear industries either, except for selected subgroups. Therefore, we have used the estimate given in ICRP27, 30 years, as the average life-shortening due to nonnuclear fatalities.

The uncertainty in life-shortening cannot be easily estimated. For occupational groups at high risk, an uncertainty of \pm 20 percent in this parameter leads to an uncertainty of \pm 15 percent in the index of harm. We are currently attempting to sharpen these estimates, using recent data on age at death for California occupational fatalities by industry. Rather than selecting, as the ICRP study did, arbitrary, constant values to rank the importance of the various harms considered, this 
study treats the issue of relative importance parametrically. It has been shown that the perception of risk depends not only on scientific evidence but on many factors, including individual and group estimates of its relative seriousness, the nature of the risk, the degree of control one has over the risk, and the relative age of and familiarity with the technologies posing the risk [6]. Until we know more about how different groups and society as a whole assess risk, it makes sense to us to create a methodology that allows different assumptions to be tested and different weights to be assigned to each harm considered. In this way, we can stretch the value of the limited and imprecise data base.

In this study, the index of harm is qualitatively defined as a measure that reflects the number of person-years lost per hundred person-years of exposure to occupationally induced injury, illness or disease, and death. The simple expressions used to calculate the index for both radiological and nonradiological industries, and under different valuations of the relative importance of different occupational harms, are discussed in Section II along with the data and their sources. The results and conclusions of the analysis are presented in section III. In Section IV, we give an illustrative example of one area in which the concept of an index of harm might prove useful--the policy decision of whether the current maximum exposure dose of $5.0 \mathrm{Rem} / \mathrm{yr}$ in the radiological "industry" should be lowered. That example, as well as the methodological work reported earlier, confirms how much more work needs to be done before an adequate degree of confidence can be placed in an index of harm. Accordingly, in section $V$, we offer a minimal list of topics that we believe merit further research. 


\section{ESTIMATING AN INDEX OF HARM}

Workers in a variety of industries are exposed to risks from a number of sources or hazards, including manufacturing processes, environmental pollutants, chemicals, and radiation. These can result in injury, illness, disease, and death. Linking cause and effect in and among industries so as to measure comparative risks is a complex task. Limited both by insufficient data and by the difficulty of weighting the relative aversions to various risks and their effects, this study nevertheless compares nonradiological with radiological occupational risks by using an index-of-harm measure.

In this section, we explain how we computed the index of harm, what simplifying assumptions had to be made, and the data we used for estimating the index for both nonradiological and radiological harms. Ideally, the index should be supported by precise data for nonradiological industries, and a credible model for radiological industries. This is not yet the case. The major contribution to nonnuclear risk is from accidental fatalities. The industry-specific fatality rates are known, but for our illustrative purposes, we have only made speculative estimates about the age of accident victims. The situation is much fuzzier for nuclear risk estimates, since the ICRP model appears to correspond to the low end of the 1972 BEIR risk scale.

\section{THEORY AND DATA ASSUMPTIONS}

The index of harm is an empirically derived measure of occupational risk in an industry. Although reducing everything that risk entails to a single index is presumptuous and imprecise at best, the benefits of comparing risk across industries and using the measure to reduce it selectively would seem to override that methodological naiveté. Moreover, it is only by attempting to develop such a measure that its imperfections can be revealed and steps taken to remedy them (such as improving data availability).

The different kinds of harm and their effects encountered in the occupational environment are perceived, and hence valued, differently 
by both technologists and laymen. * Therefore, instead of trying to rank-order the harms in some way, we have concentrated on one common effect they produce--days lost from work. In the case of premature death, we calculate lost days using the mean life expectancy (for men or women, as appropriate); in other cases, we look at data of days lost from work. Reducing harm to the common denominator of days lost from work does not preclude making value choices regarding the events that cause such work and life loss; the problem's complexity is not so easily handled.

The index of harm, I, developed in this report is a function of $x_{i}$, the fraction of years lost in industry $i$ from any cause or event by a population exposed to those causes or events for a period of one year. (We assume a year has 250 working days.) We also assume that the harm contributed by each major occupational cause is additive when measured in terms of lost work time. We can thus write:

$$
\begin{aligned}
I\left(x_{i}\right) & \equiv \sum_{j=i}^{6} I\left(x_{i j}\right) \\
& =\sum_{j=i}^{6} a_{k j} n_{i j} x_{i j},
\end{aligned}
$$

where $a_{k j}=a$ weighting factor that reflects the $k$ th assumption (from a set of 5) about the relative importance of lost days from work from the jth harm (the 6 harms and 5 assumptions are discussed below);

$n_{i j}=$ the proportion of the occupational population in the ith industry exposed to the $j$ th harm; and

$x_{1 j}=$ the number of person-years lost per hundred people in the ith industry from the $j$ th harm during a one year (250 workday) exposure.

\footnotetext{
* For example, it has been shown that different kinds of risk are valued differently. In a preliminary study exploring the nature of risk, the least desirable type of risk was found to be exposure to radiation, followed in order by exposure to toxic chemicals, fire, drowning, and finally accidental physical injury [6].
} 
Because the method of calculating $I\left(x_{i}\right)$ is different for radiological and nonradiological harms (the populations exposed to each type are different) the remainder of this section is divided into two parts. The first part shows how we evaluate $\mathrm{Eq}$. (2) for nonradiological harms; the second part, for radiological harms.

\section{NONRADIOLOGICAL HARMS}

Workers in all eight American industry classifications are susceptible to the three principal nonradiological harms considered in this study--fatality, accidental injury, and illness or disease. (Table 1 lists all the harms considered.) We assume the average 1975 employment in those industry classifications is an adequate representation of the numbers of workers exposed to those harms, and consequently we have used those figures in the analysis (both the average employment data and industry classifications are given in Table 2).

The data on conventional nonradiological fatalities, injuries, and illness have been obtained from Refs. 2 through 5, and 8 through 11 and are summarized in Table 3. We have assumed that each fatality leads to an average of 30 years of life-shortening. This is the figure suggested in ICRP27. Accidental death rates appear to be well documented, but the uncertainty of life-shortening suggests that at best, onesignificant-figure accuracy for $j=1$ is warranted. In addition, average values over the period 1972-1975 have been used. ${ }_{\text {: }}^{*}$ These form the $\mathrm{x}_{1 \mathrm{j}}$ component of the index for harms 1-3 and industries 1-8.

Because all workers in these industries are exposed to these three basic harms, but not to the same degree, it is difficult to compute values for $n_{i j}$. However, assuming a value of one for these industries and harms is reasonable and well within the accuracy of this first-cut evaluation.

The purpose of assigning arbitrary values to the weighting variable $a_{k j}$ was to give us some flexibility in the way we valued various harms.

* In this preliminary analysis we have not taken into account the potentially large interindustry variations these averages may mask. 
Table 1

TYPES OF HARM

\begin{tabular}{|c|c|}
\hline $\begin{array}{l}\text { Harm } \\
\text { Index } \\
(j)\end{array}$ & Type of Harm \\
\hline & Nonradiological \\
\hline $\begin{array}{l}1 \\
2 \\
3\end{array}$ & $\begin{array}{l}\text { Fatality } \\
\text { Accidental injury } \\
\text { Occupational illness or disease } \\
\text { Radiological }\end{array}$ \\
\hline $\begin{array}{l}4 \\
5 \\
6\end{array}$ & $\begin{array}{l}\text { Somatic effects of radiation } \\
\text { Genetic effects of radiation } \\
\text { Somatic effects of radiation to } \\
\text { fetus or embryo of pregnant } \\
\text { women }\end{array}$ \\
\hline
\end{tabular}

Table 2

AVERAGE EMPLOYMENT BY INDUSTRY FOR CALENDAR YEAR 1975

\begin{tabular}{c|l|r}
\hline $\begin{array}{c}\text { Industry } \\
\text { Index } \\
(i)\end{array}$ & \multicolumn{1}{|c|}{ Industry } & $\begin{array}{c}\text { Number of } \\
\text { Workers } \\
\text { (thousands) }\end{array}$ \\
\hline & Nonradiological Industries: & \\
1 & AF\&F & $1,568.0$ \\
2 & Mining & 745.0 \\
3 & Construction & $3,457.0$ \\
4 & Transportation & $4,498.0$ \\
5 & Trade & $16,947.0$ \\
6 & Finance & $4,223.0$ \\
7 & Services & $13,700.8$ \\
8 & Manufacturing & $18,347.0$ \\
9 & Radiozogical "Industry": & 78.5 \\
& Power reactors & 53.0 \\
& Industrial radiographers & 9.1 \\
& Reprocessing & 12.1 \\
& Manufacturing & 4.3 \\
\hline
\end{tabular}

SOURCE: For industries 1-8, Refs. 2-5; for radiological "industry," Ref. 7.

${ }^{a}$ Excluding medical applications, where patient exposure is voluntary and primarily beneficial, and cosmic radiation received by airline pilots and frequent air travelers. 
Table 3

PERSON-YEARS LOST PER 100 PERSON-YEARS BY NONRADIOLOGICAL INDUSTRY AND TYPE OF HARM, 1972-1975

\begin{tabular}{|c|c|c|c|c|}
\hline \multirow{2}{*}{$\begin{array}{l}\text { Industry } \\
\text { Index } \\
\text { (i) }\end{array}$} & \multirow[b]{2}{*}{$\begin{array}{c}\text { Industry and } \\
\text { Year }\end{array}$} & \multicolumn{3}{|c|}{$\begin{array}{c}\text { Person-Years Lost per Hundred Person-Years } \\
\text { in One Year of Occupational Exposure, } \\
x_{i j} \text {, by Type of Harm }\end{array}$} \\
\hline & & $\begin{array}{l}\text { Fatalitya } \\
(j=1)\end{array}$ & $\begin{array}{l}\text { Injury } \\
(j=2)\end{array}$ & $\begin{array}{l}\text { Disease } \\
(j=3)\end{array}$ \\
\hline 1 & $\begin{array}{l}\text { AF\&F } \\
1972 \\
1973 \\
1974 \\
1975 \\
1972-1975 \text { Mean }\end{array}$ & $\begin{array}{l}0.96 \\
0.75 \\
0.84 \\
1.05 \\
\\
0.90\end{array}$ & $\begin{array}{l}0.29 \\
0.27 \\
0.29 \\
0.24 \\
0.27\end{array}$ & $\begin{array}{l}0.013 \\
0.014 \\
0.010 \\
0.012 \\
0.012\end{array}$ \\
\hline 2 & $\begin{array}{l}\text { Mining } \\
1972 \\
1973 \\
1974 \\
1975 \\
\end{array}$ & $\begin{array}{l}(\mathrm{b}) \\
2.04 \\
2.04 \\
1.83 \\
1.97\end{array}$ & $\begin{array}{l}0.48 \\
0.48 \\
0.37 \\
0.45 \\
0.43\end{array}$ & $\begin{array}{l}0.040 \\
0.050 \\
0.060 \\
0.040 \\
0.050\end{array}$ \\
\hline 3 & $\begin{array}{l}\text { Construction } \\
1972 \\
1973 \\
1974 \\
1975 \\
\\
1972-1975 \text { Mean }\end{array}$ & $\begin{array}{l}1.53 \\
1.00 \\
1.17 \\
0.99 \\
1.17\end{array}$ & $\begin{array}{l}0.35 \\
0.39 \\
0.39 \\
0.39 \\
0.38\end{array}$ & $\begin{array}{l}0.009 \\
0.007 \\
0.007 \\
0.006 \\
0.007\end{array}$ \\
\hline 4 & $\begin{array}{l}\text { Transportation } \\
1972 \\
1973 \\
1974 \\
1975 \\
1972-1975 \text { Mean }\end{array}$ & $\begin{array}{l}0.84 \\
0.81 \\
0.78 \\
0.72 \\
\\
0.79\end{array}$ & $\begin{array}{l}0.28 \\
0.33 \\
0.36 \\
0.35 \\
0.33\end{array}$ & $\begin{array}{l}0.006 \\
0.005 \\
0.005 \\
0.004 \\
0.005\end{array}$ \\
\hline 5 & $\begin{array}{l}\text { Trade } \\
1972 \\
1973 \\
1974 \\
1975 \\
\end{array}$ & $\begin{array}{l}0.15 \\
0.20 \\
0.15 \\
0.18 \\
0.17\end{array}$ & $\begin{array}{l}0.14 \\
0.15 \\
0.14 \\
0.15 \\
0.15\end{array}$ & $\begin{array}{l}0.004 \\
0.003 \\
0.004 \\
0.003 \\
\\
0.004\end{array}$ \\
\hline
\end{tabular}


Table 3--Continued

\begin{tabular}{|c|c|c|c|c|}
\hline \multirow{2}{*}{$\begin{array}{l}\text { Industry } \\
\text { Index } \\
\text { (1) }\end{array}$} & \multirow[b]{2}{*}{$\begin{array}{c}\text { Industry and } \\
\text { Year }\end{array}$} & \multicolumn{3}{|c|}{$\begin{array}{c}\text { Person-Years Lost per Hundred Person-Years } \\
\text { in One Year of Occupational Exposure, } \\
X_{1 j} \text {, by Type of Harm }\end{array}$} \\
\hline & & $\begin{array}{l}\text { Fatality } \\
(j=1)\end{array}$ & $\begin{array}{l}\text { Injury } \\
(j=2)\end{array}$ & $\begin{array}{l}\text { Disease } \\
(j=3)\end{array}$ \\
\hline 6 & $\begin{array}{l}\text { Finance } \\
1972 \\
1973 \\
1974 \\
1975 \\
1972-1975 \text { Mean }\end{array}$ & $\begin{array}{l}0.06 \\
0.09 \\
0.09 \\
0.09 \\
0.08\end{array}$ & $\begin{array}{l}0.037 \\
0.041 \\
0.040 \\
0.043 \\
0.040\end{array}$ & $\begin{array}{l}0.002 \\
0.002 \\
0.001 \\
0.001 \\
\\
0.002\end{array}$ \\
\hline $\begin{array}{l}7 \\
\cdots\end{array}$ & $\begin{array}{l}\text { Services } \\
1972 \\
1973 \\
1974 \\
1975 \\
1972-1975 \text { Mean }\end{array}$ & $\begin{array}{l}0.15 \\
0.12 \\
0.18 \\
0.09 \\
0.14\end{array}$ & $\begin{array}{l}0.10 \\
0.11 \\
0.11 \\
0.12 \\
0.11\end{array}$ & $\begin{array}{l}0.005 \\
0.006 \\
0.004 \\
0.006 \\
\\
0.005\end{array}$ \\
\hline 8 & $\begin{array}{l}\text { Manufacturing } \\
1972 \\
1973 \\
1974 \\
1975 \\
1972-1975 \text { Mean }\end{array}$ & $\begin{array}{l}0.24 \\
0.20 \\
0.20 \\
0.21 \\
0.21\end{array}$ & $\begin{array}{l}0.24 \\
0.27 \\
0.29 \\
0.29 \\
0.26\end{array}$ & $\begin{array}{l}0.009 \\
0.009 \\
0.010 \\
0.012 \\
0.010\end{array}$ \\
\hline
\end{tabular}

SOURCE : Refs. 2-5, 8-11.

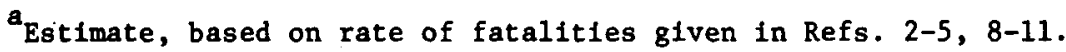
Estimate assumes that each fatality reduces $11 \mathrm{fe}$ expectancy by 30 years.

bining data for 1972 do not include coal, lignite or metal mining, and thus are not included in calculating the mean.

Because we wanted to test assumptions involving all six harms, we decided to assign values among all six "components" such that:

$$
a_{k}=\sum_{j=i}^{6} a_{k j}=1
$$

for each assumption $k=1$ to 5 . Table 4 summarizes both the assumptions and values assigned to each $a_{k j}$. The assumptions themselves were derived from concerns expressed in the literature and by colleagues. Assumption 1 weights each harm equally and acts as a reference case. In each of the remaining four assumptions, a specific harm has been singled out for emphasis and has been arbitrarily weighted ten times 
Table 4

ASSUMPTIONS AND WEIGHTS FOR EACH TYPE OF HARM

\begin{tabular}{|c|c|c|c|c|c|c|c|}
\hline \multirow{2}{*}{$\begin{array}{l}\text { Weighting } \\
\text { Index } \\
\text { (k) }\end{array}$} & \multirow{2}{*}{ Weighting Assumptions } & \multicolumn{6}{|c|}{$\begin{array}{l}\text { Assessed Values for Weighting } \\
\text { Factor } a_{k j} \text { by Type of Harm } j\end{array}$} \\
\hline & & 1 & 2 & 3 & 4 & 5 & 6 \\
\hline 1 & Equal weightings & $1 / 6$ & $1 / 6$ & $1 / 6$ & $1 / 6$ & $1 / 6$ & $1 / 6$ \\
\hline 2 & $\begin{array}{l}\text { Radiation damage to fetus } \\
\text { and embryo of pregnant } \\
\text { women perceived as high- } \\
\text { est risk }\end{array}$ & $1 / 15$ & $1 / 15$ & $1 / 15$ & $1 / 15$ & $1 / 15$ & $2 / 3$ \\
\hline 3 & $\begin{array}{l}\text { Death perceived as } \\
\text { highest risk }\end{array}$ & $5 / 12$ & $1 / 24$ & $1 / 24$ & $5 / 12$ & $1 / 24$ & $1 / 24$ \\
\hline 4 & $\begin{array}{l}\text { Death from radiation } \\
\text { perceived as highest } \\
\text { risk }\end{array}$ & $1 / 15$ & $1 / 15$ & $1 / 15$ & $2 / 3$ & $1 / 15$ & $1 / 15$ \\
\hline 5 & $\begin{array}{l}\text { Genetic damage perceived } \\
\text { as highest risk }\end{array}$ & $1 / 15$ & $1 / 15$ & $1 / 15$ & $1 / 15$ & $2 / 3$ & $1 / 15$ \\
\hline
\end{tabular}

${ }^{a}$ Affects all women of child-bearing age.

more heavily than the others. For example, for $k=3$, death $(j=1$ and 4) was singled out; for $k^{2}=4$ the emphasis was only on death by radiation $(j=4)$. Treating the assumptions parametrically in this way allows us to take into account the variations in aversion that different individuals and groups may have toward the harm. Our formulation would permit others to experiment with different harms and still other assumptions. For example, values for $a_{k j}$ for each assumption need not sum to unity; furthermore, the harm singled out for emphasis could be weighted by a value other than ten. Although the cases and values we have chosen for this report are arbitrary, they do illustrate the use of the methodology and hence serve our purpose.

\section{RADIOLOGICAL HARMS}

Risk from exposure to radiation increases with the radiation dose, measured in Rem/yr. For this reason, we treat the dose parametrically, choosing reference values of specific significance: 


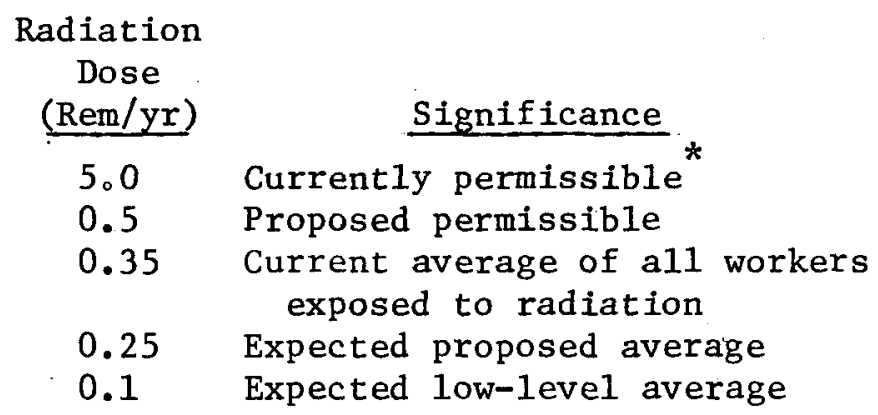

The figure of $0.35 \mathrm{Rem} / \mathrm{yr}-$ the current average dose of all workers exposed to radiation--is derived from the data in Table 8 ( $\mathrm{p}$. 27). There, the average individual doses lie between 0.23 and 0.40 but are skewed toward the high end of the range. The figure of $0.25 \mathrm{Rem} / \mathrm{yr}$ as the expected proposed average is our own estimate, given no data on the distribution of doses under a reduced limit. However, if dropping the allowable limit from 5.0 to $0.5 \mathrm{Rem} / \mathrm{yr}$ has even a small effect, we assert that the average industry dose could be reduced by perhaps 0.1 Rem/yr.

This analysis treats three kinds of radiological harms--somatic effects of radiation, its genetic effects, and its somatic effects on

\footnotetext{
*In the United States, the National Council on Radiation Protection and Measurement (NCRPM) proposes exposure standards, often in conjunction with other groups such as the International Commission on Radiological Protection (ICRP) and the United Nations Scientific Committee on the Effects of Atomic Radiation (UNSCEAR). The NCRP's 1949 report recognized for the first time that radiation protection criteria depended not only on biomedical and physical factors but also on value judgments. As the genetic effects of radiation became better understood, the NCRP lowered the maximum permissible dose equivalent in 1957, with which compliance was then technically feasible. At about this time, various governmental agencies began to incorporate NCRP recommendations as standards in codes and regulations. In 1972, both UNSCEAR and the Committee on Biological Effects of Ionizing Radiation (BEIR) of the National Academy of Sciences issued reports presenting for the first time risk estimates for radiation carcinogenesis and radiation-induced genetic effects in human beings, followed in 1977 by ICRP's Publication No. 27 with its innovative but limited index-of-harm concept.

It should also be noted that the $5.0 \mathrm{Rem} / \mathrm{yr}$ shown in the radiation dose table is not the actual maximum annual dose (currently $12 \mathrm{Rem} / \mathrm{yr}$ ) but the average annual dose spread over a worker's lifetime after age 18. For simplicity in record-keeping, NRC allows $5.0 \mathrm{Rem} / \mathrm{yr}$ to be used instead.
} 
the fetus or embryo of pregnant women (see Table 1). Clearly, the populations exposed to these harms are only those exposed to any kind of radiation (excluding medical applications), and such workers are found in all eight industry classifications. However, the numbers of any such people are a minute fraction of the occupational work force-78,500 persons susceptible to radiological exposure in 1975 out of about 63 million workers (see Table 2).

Unfortunately, there are no empirical data available on the effects of these radiological harms on this exposed population (as we have pointed out earlier, low-level radiation produces principally delayed effects, making such data collection extremely difficult and, in the short run, impossible). Our strategy in forming a comparison of available ICRP/BEIR models with the empirical effects of nonradiological harms was simply to be able to apply the methodology to radiological harms. To take into account the accompanying uncertainty in the estimates, we have performed a simple sensitivity analysis on those data and describe the results below.

The data we have used for estimating the effects of the radiological harms have been normalized from Ref. 1, the ICRP study, to denote the person-years lost per 100 person-years for one year of occupational exposure. We show the normalized data as the "reference" case for each effect in Table 5; in adjacent columns labeled "lesser effect" and "greater effect," we have multiplied the figures in the reference column by 0.5 and 5.0 , respectively. In this way, we can begin to judge the effect of viewing the accuracy of the ICRP parameters optimistically or pessimistically. The reference ICRP estimate is based on multiplying an estimated death rate of $10^{-4}$ per Rem by 15 years life-shortening. This value of $10^{-4}$ appears to correspond to the lowest estimated rate that can be made using BEIR parameters (absolute risk model, with plateau). The upper bound estimate could be a factor of 2 or 3 times this figure.

The data for radiation-induced somatic effects reflect only their stochastic or random component. (Nonstochastic or "linear" effects, which can occur only on exposure to doses above some threshold, say 25 Rem/yr, are unlikely to be a factor within present allowable limits, 
Table 5

PERSON-YEARS LOST PER 100 PERSON-YEARS BY TYPE OF RADIATION-INDUCED EFFECT AND RADIATION DOSE

\begin{tabular}{|c|c|c|c|}
\hline \multirow{2}{*}{$\begin{array}{l}\text { Annual } \\
\text { Exposure } \\
\text { Dose } \\
\text { (Rem/yr) }\end{array}$} & \multicolumn{3}{|c|}{$\begin{array}{l}\text { Person-Years Lost per } 100 \text { Person-Years During } \\
\text { One Year of Occupational Exposure, X } 9 j \text {, by } \\
\text { Type of Radiation-Induced Effect }\end{array}$} \\
\hline & Lesser Effect ${ }^{a}$ & Reference ${ }^{b}$ & Greater Effectc \\
\hline \multicolumn{4}{|c|}{ Somatic $(j=4)$} \\
\hline $\begin{array}{l}5.0 \\
0.5 \\
0.35 \\
0.25 \\
0.1\end{array}$ & $\begin{array}{l}0.375 \\
0.038 \\
0.027 \\
0.019 \\
0.008\end{array}$ & $\begin{array}{l}0.750 \\
0.075 \\
0.053 \\
0.038 \\
0.015\end{array}$ & $\begin{array}{r}3.750 \\
0.375 \\
0.265 \\
0.190 \\
0.075\end{array}$ \\
\hline \multicolumn{4}{|c|}{ Genetic $(j=5)^{\mathrm{d}}$} \\
\hline $\begin{array}{l}5.0 \\
0.5 \\
0.35 \\
0.25 \\
0.1\end{array}$ & $\begin{array}{l}0.113 \\
0.012 \\
0.008 \\
0.006 \\
0.003\end{array}$ & $\begin{array}{l}0.225 \\
0.023 \\
0.016 \\
0.011 \\
0.005\end{array}$ & $\begin{array}{l}1.125 \\
0.115 \\
0.080 \\
0.055 \\
0.025\end{array}$ \\
\hline
\end{tabular}

Somatic to Embryo or Fetus of Pregnant Women $(j=6)$

\begin{tabular}{l|l|l|l}
\hline 5.0 & 0.080 & 0.160 & 0.800 \\
0.5 & 0.008 & 0.016 & 0.080 \\
0.35 & 0.006 & 0.011 & 0.055 \\
0.25 & 0.004 & 0.007 & 0.035 \\
0.1 & 0.002 & 0.002 & 0.015 \\
\hline
\end{tabular}

\footnotetext{
aqual to one-half the reference case, rounded to three decimal places.

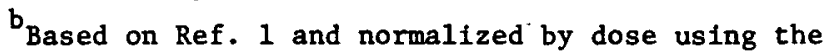
linear radiation-risk hypothesis. ICRP fatality est1mates correspond to lowest BEIR case.

Equal to five times the reference case.

d Calculated for two-generation effects.
}

and thus are ignored.) Stochastic effects can raise the incidence of cancers in people exposed to low-level radiation, and could result in premature death.

Radiation-induced genetic damage is distinguished from teratogenic effects in that the former applies to both men and women, either of whom could pass genes and chromosomes damaged by radiation to their offspring. The latter applies only to fertile women, especially pregnant women, and affects the ovum, embryo, or fetus directly. Thus, the latter type of damage is somatic in nature; the former genetic. 
Radiation damage to fertile women may, if severe enough, prevent the development or implantation of the fertilized ovum, cause abortion of a nonviable fetus, or result in a liveborn child with genetic abnormalities. Because of lack of data, however, calculation of the harm resulting from both types of damage depends critically on subjective judgment. For example, we do not know to what extent second- and thirdgeneration offspring are affected by genetic, embryotic, or fetal damage, especially when more than one damaged offspring may result.

The figures in Table 5 are all we have as proxies in this highly uncertain area. Somatic stochastic effects seem to have the potential for more harm than the other two kinds added together, although our simplistic measurement of harm does leave out many important considerations. 
III. RESULTS AND CONCLUSIONS

\section{RESULTS}

Table 6 and Figure 1 together present the computed indexes of harm under the five different weighting assumptions for both radiological and nonradiological industries using the reference ICRP dose/risk model. Table 6 shows the results numerically; the figure depicts the industry rankings graphically by individual assumption as defined in Table 4 . We point out again that the ICRP fatality rate appears to correspond to the lowest bounding estimate of BEIR II (Absolute Risk-Plateau Mode1) [12].

Under two of the five assumptions tested, the mining industry is found to have the highest index of harm; under a third assumption, it comes very close to registering the highest index. The true index of harm for the mining industry--and for must of the others--may be understated, in view of current controversies over the extent of occupationally-induced diseases. Even so, mining appears to be the riskiest industry under all assumptions.

Judging from the rankings under all five assumptions, and using the reference ICRP dose/risk model, the industry occupational risk leaders seem to be mining, $A F \& F$, construction, transportation, and manufacturing, while the radiological "industry" at its current average dose level of around $0.35 \mathrm{Rem} / \mathrm{yr}$ is among the least risky. The point of including results for a dose level at the exposure limit of 5.0 Rem/yr is to show that even if such conditions existed, the radiological "industry" would stizl not be the riskiest if the ICRP estimate is valid. At that level of exposure, it is a clear leader where death from radiation is weighted most heavily; in the case of two other assumptions--weighting most heavily in turn genetic damage, and somatic damage to the fetus and embryo of pregnant women--it is only slightly riskier than mining. However, we wish to emphasize that the results 
Table 6

INDEXES OF HARM FOR RADIOLOGICAL AND NONRADIOLOGICAL INDUSTRIES UNDER SELECTED ASSUMPTIONS

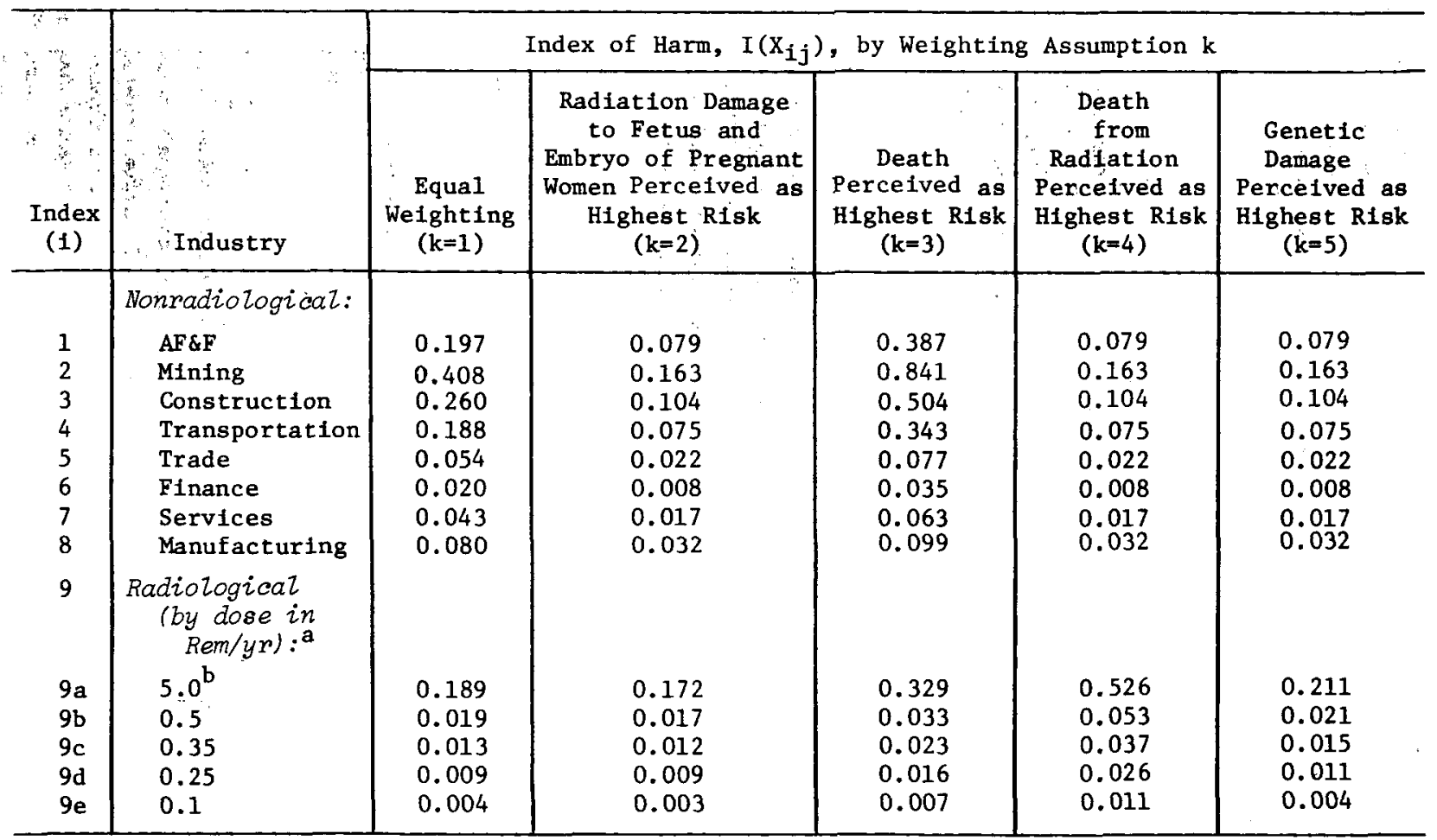

a These reference cases represent ICRP estimates of nuclear fatality rates corresponding to lower bound BEIR II estimates.

$\mathrm{b}_{\text {This }}$ represents a regulatory limit and is not indicative of general industry practice. 


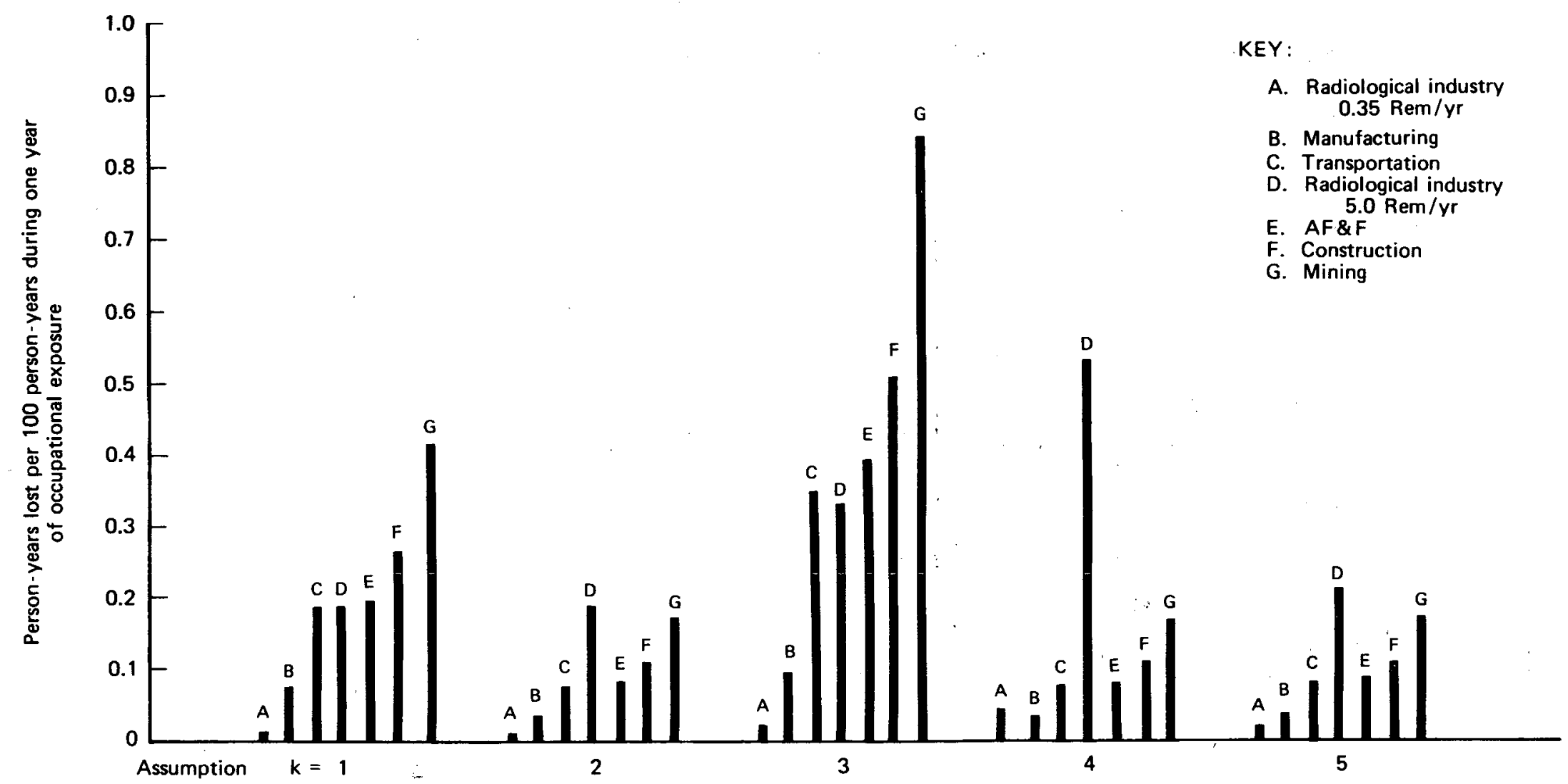

Fig. 1 - Index-of-harm industry rankings for each of five assumptions (Source: Table 6) ICRP Reference Case: Nuclear fátality rates corresponding

to the lowest risk model proposed in BEIR II 
at an average exposure dose of $5.0 \mathrm{Rem} / \mathrm{yr}$ should not be taken to imply that any group is actually exposed to such a level over time. Exposure at that level is fictitious, because nowhere is an occupational group exposed to radiation at that level day after day or subjected to an average level that high.

The principal feature of both Table 6 and Figure 1 is that the Indexes of harm of the top five industries with respect to nonradiological harms are far more sensitive to the different assumptions than is the radiological "industry" at its current $0.35 \mathrm{Rem} / \mathrm{yr}$ average exposure dose, referred to as the "low risk" ICRP reference model.

Table 7 shows the results from Table 6 under assumption $k=1$ separately, with the ICRP dose/risk parameter multiplied by factors of 0.5 and 5.0 as proxies for optimistic and pessimistic views of the ICRP estimates. Instead of the discrete values we had before, we now show ranges of values that more appropriately reflect the uncertainty inherent in the ICRP data. Even at the highest point in its range, the Index of harm at the $0.35 \mathrm{Rem} / \mathrm{yr}$ exposure level still has a value lower than the indexes of five nonradiological industries. Precisely at what point in the range one feels comfortable making the comparison depends almost entirely, in the absence of empirical evidence, on both one's fear of cancer and other radiation-induced effects, and on the allowance one makes for delayed effects in formulating the index. Some researchers are asserting that the linear hypothesis is not conservative after all and that the risks at low levels of radiation are much greater than linear extrapolations would indicate [13, p. 160]. Others assert the opposite. Precisely how much greater or less is a question still to be answered.

\section{CONCLUSIONS}

The index-of-harm methodology developed in this study has been applied to U.S. Industry lost-year statistics with respect to nonradiological harms, and to the ICRP/dose-response model for radiationinduced harms (workers exposed to the latter types of harm comprise a mere fraction of all occupational workers in the United States). 
Table 7

\section{INDEXES OF HARM FOR NONRADIOLOGICAL INDUSTRIES \\ COMPARED WITH INDEX-OF-HARM RANGES FOR RADIOLOGICAL INDUSTRY BY DOSE LEVEL, UNDER EQUAL WEIGHTING ASSUMPTION}

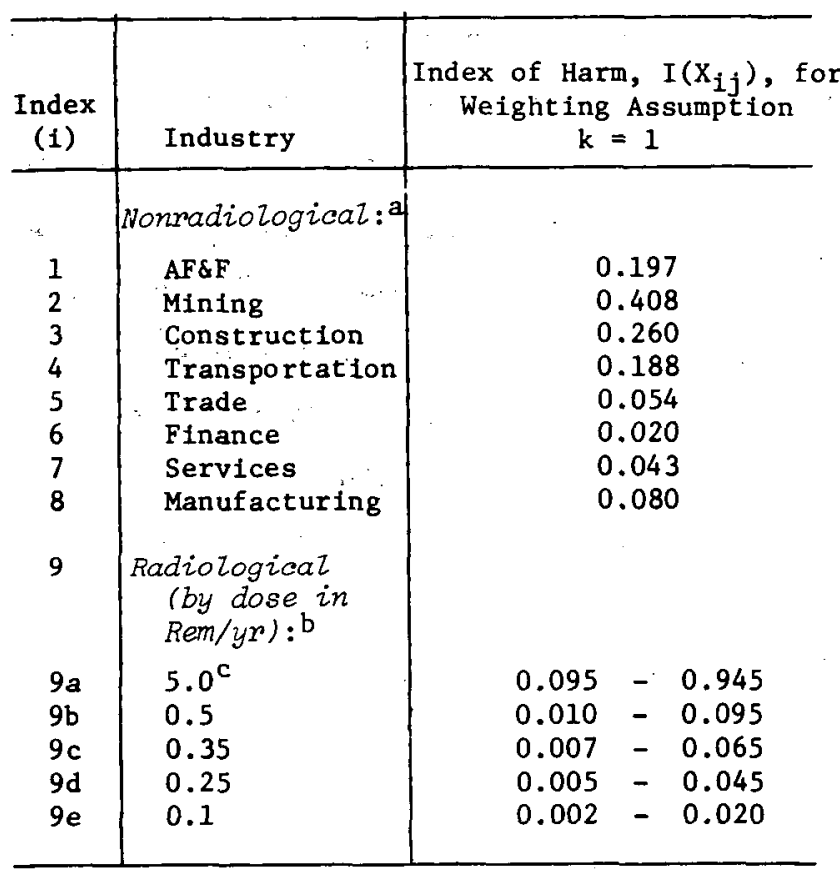

\footnotetext{
$a_{\text {Data }}$ for nonradlological industries taken from Table 6, col. 1 .

$b_{\text {Ranges derived from ICRP estimates shown in }}$ Table 6, col. 1; lower and upper ends are ICRP values multiplied by factors of 0.5 and 5.0 respectively.

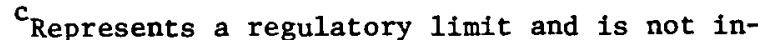
dicative of general industry practice.
}

Because of great uncertainty associated with the ICRP estimate, and its potential bias on the side of low radiological risk, we developed an appropriate range of indexes as proxies for optimistic and pessimistic views of those data.

The index was computed by summing the effect of a number of harms appropriate to the occupational environment of those industries, and properly based on the subpopulation likely to experience those harms. Its principal virtue is that it can be compared across industries. Further, the weighting factor for valuing the harms has been included 
here as a variable, enabling us to vary it parametrically depending on the number, types, and perceived severity of the harms considered.

This last feature is at the same time the study's greatest strength and weakest point. The values we have ascribed to our various assumptions have been arbitrary, yet the issues are desperately important. Is death from radiation, for example, worse than death from other causes? Or is death the same by any name? Would we view with indifference the same number of days lost from accidental injury as from radiation-induced somatic effects? Is death from radiation more or less acceptable than the genetic damage radiation can cause? And how might one place a value on the life of an offspring (of a first or subsequent generation) which may be either deformed, retarded, or damaged genetically? To the extent that questions such as these can be posed and data gathered to address them, our perception of risk will change and so will the process of setting industrial safety standards.

The limitations associated with the index of harm can best be appreciated by the variety of ways we could have derived it. For example, we could have based it on the entire radiological "industry" or just part of it; on all kinds of risk or just those from radiation; on a valuation of occupational risks either equal to or above those experienced by the general population; or on some absolute scale, or one relative to other natural risks. Depending on how those issues are handled and hence how risk is perceived, the values calculated for an index of harm will differ.

In the end, risk is perceived differently by different individuals, and what may be an acceptable risk for people in one industry may not be so viewed by those in another, even if the sizes of the two industries are roughly equal:

The index of harm developed in this report can be a flexible and useful tool in risk analysis. It could conceivably be used in a number of potentially useful ways, three of which are:

- To compare the relative risk of occupational workers exposed to different kinds of harm (as in this report); the index reduces to a common denominator the effects of harms that hitherto 
could not be compared. Moreover, using a parametric approach enables different perceptions and valuations of risk to be treated and evaluated.

- To evaluate the "benefit" side of a cost-benefit equation by using the index to estimate a particular strategy's potential for reducing occupational risk. Questions such as which harms should have their effects reduced and by how much (in addition to evaluating alternative means to accomplish such ends) could be analyzed in a broad way.

- To expand the formulation of the index to include both immediate and delayed effects of both radiological and nonradiological harms whenever appropriate data become available. Developing the methodology in this and other ways would yield a more precise and reliable indicator.

The principal finding of this study's interindustry comparison of risk is that at current levels of radiation exposure and based on the apparently low ICRP estimates of the dose-harm relationship, the radiological "industry" ranks among the less risky industries (note that the rankings change, however, when our more pessimistic risk estimates are used). It could thus be argued that a more cost-effective solution from society's standpoint would be to make the riskier industries safer. For example, it has been reported that radiological workers' latent cancer risks are lower than an average worker's actual risk of fatal occupation accidents, * and that the average actual risk to radiological workers is no higher than the average risk from fatal industrial diseases in nonradiological industries. ${ }^{\dagger}$ Even if the ICRP estimates are regarded pessimistically and an index of harm five times as large as the 0.35 Rem/yr average-dose level (Table 7) is assumed, the radiological "industry" is shown to be relatively safe. In light of the recent, and somewhat divided, findings of the Committee on the Biological Effects

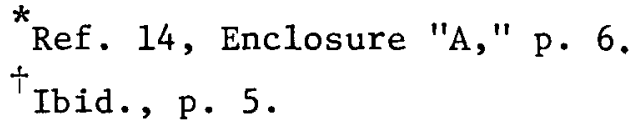


of Ionizing Radiation (BEIR) [15] as presented in the recent BEIR-III report, a factor of 5 appears to represent a reasonable approximation of the range of uncertainty. However, we have not considered the actual range of the BEIR-III results explicitly in our work. Furthermore, as discussed earlier, the rankings are altered considerably at the regulatory dose level.

Overall, given more robust data and a more refined formulation of the index, we believe the methodology we have developed here may become a useful tool in analyzing and comparing occupational risks across industries. The next two sections together explore further work that needs to be done and the improvements possible in the index. 
IV. AN ILLUSTRATIVE EXAMPLE

Although we strongly believe that the extensions to the index-ofharm methodology described in this report are in the right direction and capable of addressing important questions, the chief factor limiting the index's usefulness now is inadequate data. But it is not the only factor. Certainly the index of harm--greatly simplified in this report precisely because so little data were available--could doubtless be further refined as more is learned about the complex nature of risk and how to measure its various facets.

One way of showing how little is yet known about risk assessment and measurement is to apply the above analysis to a specific example. The one we have chosen was suggested in early 1978 when the Nuclear Regulatory Commission (NRC) first wished to open rulemaking proceedings and hold hearings on whether workers in nuclear facilities and, to a lesser extent, those in nonradiological industries should be exposed to substantially less risk from radiation. The NRC is expected to consider a National Resources Defense Council motion to lower the maximum allowable occupational radiation dose tenfold from 5.0 to 0.5 Rem/yr. This example, in exploring whether we have sufficient basis for lowering that limit, concludes that the actual quantification of the net risk reduction resulting from such a step cannot be made without more relevant estimates. Our index-of-harm analysis can provide some of those estimates.

The maximum allowable whole-body dose to which workers in radiological occupations are subject has been declining steadily over the last half century $[16, p \cdot 146]$ :

$\begin{array}{cc}\text { Period } & \begin{array}{c}\text { Maximum Allowable } \\ \text { Whole-Body Dose } \\ \text { (Rem/yr) }\end{array} \\ 1931-1936 & 60 \\ 1937-1948 & 30 \\ 1949-1957 & 15 \\ 1957-1978 & 5\end{array}$


This historical trend may not continue as a matter of course; any further reduction in the maximum dose limit may have to be justified on grounds of risk-cost-benefit considerations. Yet, as we have seen, measuring radiologic:al risk and assessing its relative severity are both difficult and subjective.

Despite the relatively low average-exposure dose of $0.35 \mathrm{Rem} / \mathrm{yr}$ experienced by workers in the U.S. radiological "industry" as a whole, and the large number: of relatively safe sites, lowering the allowable exposure dose across; the board would still affect a few select workers at each site whose exposure is well above the average (such high individual doses are masked by the average-exposure figures for particular sites).* Lowering the standard therefore implies limiting the dosage of high-exposure workers with at least the following cost implications:

- Adopting any one of a number of retrofit strategies, including the use of new tools, designing new shielding, longer reactor cooldown periods before maintenance, and increasing maintenance efficiency.

- Hiring additional (and initially less experienced) personnel to share and thus reduce the individual radiation dose experienced by high-exposure workers. (It is believed that NRC licensees would prefer this apparently less costly solution to others in the event the allowable exposure dose were lowered. ${ }^{\dagger}$ Yet, if demand outstripped supply for such skilled workers, the costs could be much higher. On the other hand, if enough extra people are not hired, reaching the annual dose limit before the end of the year becomes a real possibility and could force the facility to shut down. It has been estimated that if the limit were reduced to $0.5 \mathrm{Rem} / \mathrm{yr}$, the cost to nuclear plant licensees alone for extra workers and extended

* $A$ radiologically hazardous site is defined as one whose workers are exposed to doses approaching $5.0 \mathrm{Rem} / \mathrm{yr}$.

†Ref. 14, Enclcsure "A," p. 7. 
plant outages during the years 1979 to 2000 could be between $\$ 23$ billion and $\$ 53$ billion.). *

- Increasing the potential for accidents and injury by using less experienced workers:

- Increasing the number of persons exposed to low-level radiation, and potentially the collective risk. (The NRC staff believe that "any regulatory action aimed at reducing occupational radiation risks should also be directed at reduction in the collective dose." Table 8 presents average individual and extrapolated collective doses by radiological "industry" licensee type. The overall risk of latent effects such as cancer appears to be associated with the number of person-rems received rather than the individual radiation dose. ${ }^{\dagger}$ )

- Reducing efficiency by wasting large portions of skilled worker time, probably the largest hidden cost of lowering the allowable dose. One highly exposed worker might put in 6.4 hours of productive work in an 8-hour shift ( 80 percent efficiency), 1.6 hours being required for setup and maneuvering in and out of the workplace. For two workers to do the same work, thereby halving the exposure of each, their efficiency would also halve to 40 percent. In the process, each would be forced to waste 3.2 hours a shift (or at least might have to be trained to perform other, potentially less valuable work away from radiation zones).

All of the above consequences appear quite costly both in real terms and in further potential risk, so that it would seem appropriate and even desirable to assess the magnitude of these costs--and who would bear them--before lowering the exposure limit. Whereas most nuclear reactors and fuel-cycle facilities would require a few physical retrofits, some older facilities may need substantial and costly modifications. Even if it were found that the costs at certain facilities would appear

\footnotetext{
*Ibid., p. 23, and Enclosure "F," p. 46.

†Ref. 14, Enclosure "A," p. 1.
} 
Table 8

AVERAGE INDIVIDUAL AND EXTRAPOLATED COLLECTIVE DOSES

FOR 1OCFR LICENSEES, 1973-1975

\begin{tabular}{c|c|c}
\hline $\begin{array}{c}\text { Type of Licensee } \\
\text { and Year }\end{array}$ & $\begin{array}{c}\text { Average } \\
\text { Individual Dose } \\
\text { (Rem/person-yr) }\end{array}$ & $\begin{array}{c}\text { Extrapolated } \\
\text { Collective Dose } \\
\text { (Person-Rem/yr) }\end{array}$ \\
\hline $\begin{array}{c}\text { Power reactors } \\
1973 \\
1974\end{array}$ & 0.32 & 14,337 \\
1975 & 0.23 & 14,083 \\
$\begin{array}{c}\text { Industrial radiog- } \\
\text { raphers }\end{array}$ & 0.39 & 21,270 \\
1973 & & \\
1974 & 0.40 & $-3,630$ \\
1975 & 0.33 & 3,030 \\
Fuel processing and & 0.31 & 3,080 \\
reprocessing & & \\
1973 & 0.23 & 2,400 \\
1974 & 0.25 & 2,739 \\
1975 & 0.27 & 3,175 \\
Manufacturing and & & \\
distribution & & 1,210 \\
1973 & 0.28 & 1,140 \\
1974 & 0.32 & 1,440 \\
1975 & 0.35 & \\
\hline
\end{tabular}

SOURCE: Ref. 7, pp. 19, 20 .

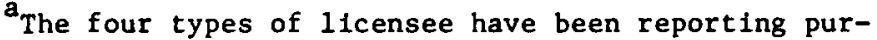
suant to \$10CFR Part 20 requirements since 1973. Prior reports included only those estimated doses in excess of $1.25 \mathrm{Rem} / \mathrm{yr}$. Does not include medical applications or cosmic-radiation doses endured by airline pilots and frequent air travelers.

prohibitive, the total financial effect of the change on the radiological industry may still be small enough to justify it. A judgment on the issue can be reached only by weighing the added costs incurred in the industry and who would bear them with the amount of risk reduction those expenditures could potentially buy.

Lowering the low-level exposure dose limit from 5.0 to $0.5 \mathrm{Rem} / \mathrm{yr}$ means reducing the radiological "industry" average dose from about 0.35 to $0.25 \mathrm{Rem} / \mathrm{yr}$. Our index-of-harm analysis showed; for each of the five assumptions examined, the following estimated reductions in the index as a consequence: 
Reduction in Index of Harm Through Lowering the Exposure Limit from 5.0 to $0.5 \mathrm{Rem} / \mathrm{yr}^{\mathrm{a}}$

Assumption

1. Al1 harms weighted equally

2. Radiation damage to fetus and embryo perceived as highest risk

3. Death perceived as highest risk

4. Death from radiation perceived as highest risk

5. Genetic damage perceived as highest risk
Absolute

0.004

0.003

0.007

0.011

0.004 $\underline{\text { Percent }}$

31

25

30

30

27

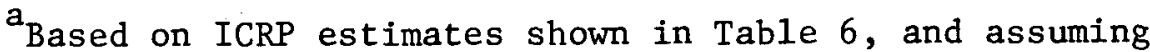
that the industry average is reduced from 0.35 to $0.25 \mathrm{Rem} / \mathrm{yr}$ ( 30 percent decrease).

The above figures show reductions in the index of between 25 and 31 percent, and indicate broadly what the costs imposed on NRC licensees due to lowering the exposure dose limit (whatever those costs are) will buy in terms of risk reduction. Because of the assumed linearity of the dose-response model, this $\sim 30$ percent reduction would be insensitive to the risk parameters. It is conceivable to imagine a somewhat more highly developed index being used in this way to provide an estimate of potential "benefits" from either a regulatory action or the implementation of some risk-reducing strategy. Hopefully, decisions in this area will be based more on rational cost-benefit analysis than on purely political or emotional grounds. A methodology that can treat subjective judgment explicitly and quantitatively--even parametrically as in this report--is a step in that direction, although by itself may be insufficient as a policy tool. Other factors, often unquantifiable, may play more decisive roles.

Whereas reducing the limit across the board may be a convenient measure, it overlooks the complicated nature of risk. The index of han developed in this report, although allowing the relative risks of injury, illness, and death to be compared across different industry 
sectors, nevertheless remains a subjective measure whose usefulness depends critically on how the various harms are valued. Occupational harms, even ones with equivalent effects, are seldom valued equally. Moreover, some kinds of harm, to which certain groups are more susceptible, are riskier overall than others. What these statements suggest is that the nature and extent of the harm, as well as who is harmed, are major determinants of the risk involved and also affect how the risk is perceived.

While blanket regulations may be convenient to enforce, it is difficult to assure that they also are equitable. Since the safety of all radiological workers is important, we suggest that additional attention focus particularly on those who receive higher-than-average doses or those most susceptible to radiation-induced damage. Accordingly, a number of alternative policies merit consideration and further detailed investigation:

- Protect women of childbearing age--especially pregnant women-from receiving any occupational radiation exposure. (The risk of dying prematurely from cancer is greater for younger than older people, and greater for women than men at all age levels (see Table 9).) Such a policy would also protect this group from the potential genetic effects of radiation."

\footnotetext{
* A major new civil rights and civil liberties issue is emerging that poses medical, legal, economic, and moral dilemmas. "The issue involves, first of all, the right of fertile women to hold jobs and not suffer discrimination. It also involves the even larger, more emotional and more portentous issue of the threat to the reproductive capacity and geretic stability of hundreds of thousands of men and women whose jobs expose them to substances that can cause sterility or cause mental or physical deformity in fetuses" [17, p. Al]. The issue appears just when women are entering industrial jobs in significantly larger numbers as a result of their struggles against job discrimination. They are now seemingly confronted, in certain jobs, "with the dismal choice of relinquishing their right to have children or their jobs" [18].

This issue is not clear-cut. Employers' intentions of protecting such women and their fetuses are being openly challenged on scientific grounds. For a variety of hazardous substances, a "safe" level of exposure cannot be determined because the data are inadequate, even
} 
Table 9

ESTIMATE OF THE RISK EFFECT OF LOW-LEVEL RADIATION AS A FUNCTION OF AGE AND SEX OF INDIVIDUALS

\begin{tabular}{l|c|c|r|r|r|r}
\hline \multirow{2}{*}{} & \multicolumn{5}{|c|}{$\begin{array}{c}\text { Person-Years Lost per Million } \\
\text { Workers per Rem }\end{array}$} \\
\cline { 2 - 7 } Sex & 20 & 30 & 40 & 50 & 60 & Mean \\
\cline { 2 - 7 } Male & 197 & 133 & 87 & 58 & 27 & 100 \\
Female & 239 & 168 & 131 & 102 & 60 & 140 \\
\hline
\end{tabular}

SOURCE: Adapted from Ref. 1, Table 13.

- Reduce the allowable dose on 1 y for young people of both sexes, say under 25 years of age, as this group is most likely, if affected by radiation, to transmit genetic damage to their offspring. Because of the long latency period, its members also possess the highest risk of dying prematurely from cancer.

- Reduce the allowable exposure dose, possibly by an amount less than a factor of 10 (to lessen what might otherwise be prohibitive costs) and apply the new standard only to those

though NIOSH (National Institute for Occupational Safety and Health) now distinguishes between 56 mutagens--substances that can damage or change genetic structures--and 471 teratogens--substances that can create physical or mental deformities [17, p. D8]. Rather than prohibit women of childbearing age from holding certain hazardous jobs-the most economical alternative open to an employer--a number of agencies including OSHA and EEOC insist that the solution should be to make the workplace safe for workers [17, p. D8].

A 1977 survey to determine the extent of sex discrimination among female industrial radiation workers concluded that "women of childbearing age are discriminated against" [19]. However, the sample was small: of 143 women who received the survey, 59 completed it, and 30 of those were or had been employed as radiation workers. Furthermore, only "'four or five' respondents . . . either had been restricted--or knew of instances where other workers had been restricted--by radiation exposure limits more stringent than those applied to their male colleagues." Nevertheless, the study draws attention to a potentially embarrassing problem, particularly in view of NRC Regulatory Guide 8.13 which recommends that "a woman who is pregnant receive not more than 0.5 Rem during pregnancy" compared with the $5.0 \mathrm{Rem} / \mathrm{yr}$ radiation 1 imit for all occupational adults. 
in the radiological "industry" currently exposed to doses higher than that standard. In addition, to guard against a rising collective risk, limits should be set appropriate to the size of licensee in total person-Rem/yr terms.*

\footnotetext{
${ }^{*}$ It has been estimated that additional workers in the nuclear reactor sector would cause increases in the collective dose of between 20 and 450 percent [14, Enclosure "A," p. 9]. And one collective-dose standard across the industry would penalize the larger licensee organizations unfairly and severely disrupt their operations [14, Enclosure "A," p. 25].
} 


\section{TOPICS FOR FURTHER RESEARCH}

The illustrative example in Section IV showed clearly the extent to which we are unable to resolve pressing issues for want of adequate data. Just in that one area, the following topics need investigating:

- A comprehensive assessment of the full costs of specific reductions in the allowable exposure limit and who would bear them. (Major cost categories include retrofit equipment, additional workers, decreased worker productivity, potentially increased collective radiation dose and risk of accidental. injury, and increased risk of outages and licensee downtime.)

o The extent to which the alternative policies suggested, or others, reduce overall risk to both occupational workers and the general population compared with an across-the-board reduction in the allowable exposure limit. Which policy would be most cost-effective?

- The development of more precise estimates of radiological risk in the nuclear-reactor industry.

- An assessment of the regulatory and legislative implications of reducing radiological exposure limits for select groups, specifically women of childbearing age. What are the specific tradeoffs between civil liberties and job rights on the one hand and costs (both to obtain more data and to comply with possibly stricter laws) and potential inflationary effects on the other?

In order to develop the methodology further to give both industry and government a more robust indicator, we would suggest further research in the following areas:

\footnotetext{
*The NRC staff believes this risk is underestimated [14, Enclosure "B," p. 4]. The nuclear risk estimates used in this report are derived from theoretical projections, whereas the risks inherent in the nonradiological industries are based on empirical data.
} 
Determine how the index of harm varies among both workers and sectors within each industry. Data for nonradiological industries are average figures that mask extreme intraindustry variations. For example, in construction, building a 90-story tower entails larger risks than building a warehouse. Including intraindustry variations may alter the way the index is formulated.

- Explore alternate ways of measuring the harm to and reducing risk for both occupational workers and the general population. Such an analysis would either strengthen the way the present index is formulated or would provide strong arguments for changing it. Candidate alternatives for measuring the effects of occupational harm include--by industry, on a societal basis, by fuel cycle, on an individual basis, or by nature of risk (as in this study).

- Perform surveys among both occupational workers in various industries and the population at large, first to elicit different ways in which various harms can be valued, and then to see whether patterns exist in the way various groups value them. The assumptions treated parametrically in this study were arbitrary and merely illustrative; substituting more realistic data would yield valuable information, and possibly also change the formulation of the index.

o Collect statistics by industry grouping on average ages at death. By comparing these data with general U.S. mortality data less immediate deaths accounted for, we could develop needed statistics for delayed mortality. Such data would help to adjust upwards the data used in Table 3 of this report which underestimates the effects of the nonradiological harms by considering only immediate and not delayed effects.

o Compare the costs of alternative strategies to reduce risk, taking into account the nature of the risk, the populations affected, and the time frame over which the strategy could be implemented. 


\section{REFERENCES}

1. "Problems Involved in Developing an Index of Harm," Annals of the International Commission on Radiological Protection, Publication No. 27, Pergamon Press, London, May 1977.

2. Occupational Injuries and Illnesses in Industry, 1972, Bulletin No. 1830, U.S. Department of Labor, Washington, D.C., 1974.

3. Occupational Injuries and Illnesses in Industry, 1973, Bulletin No. 1874, U.S. Department of Labor, Washington, D.C., 1975.

4. Occupational Injuries and Illnesses in Industry, 1974, Bulletin No. 1932, U.S. Department of Labor, Washington, D.C., 1976.

5. Occupational Injuries and IZInesses in Industry, 1975, Bulletin No. 1981, U.S. Department of Labor, Washington, D.C., 1978.

6. Solomon, K. A., Inferming a Level of Acceptable Risk, The Rand Corporation (forthcoming).

7. Coo1, Walter S., Occupational Radiation Exposure at NRC-Licensed Facizities, Office of Standards Development, U.S. Nuclear Regulatory Commission, 1975.

8. California Work Injuries, 1970, Division of Labor Statistics, Sacramento, California, March 1972.

9. California Work Injuries, 1971, Division of Labor Statistics, Sacramento, California, December 1972.

10. Califormia Work Injuries, 1972, Division of Labor Statistics, Sacramento, California, February 1974.

11. "Health and Work in America," APHA Chart Book, presented at the 103d Annual Meeting of the American Public Health Association in Chicago, November $16-20,1975$.

12. Committee on Biological Effects of Ionizing Radiation (BEIR), The Effects on Populations of Exposure to Low Levels of Ionizing Radiation, National Academy of Sciences, National Research Council, Washington, D.C., November 1972.

13. Marx, Jean L., "Low-Level Radiation: Just How Bad Is It?" Seience, Vo1. 204, April 13, 1979, pp. 160-164.

14. Minogue, Robert B., "Further Actions to Control Risks Associated with Occupational Radiation Exposures in NRC-Licensed Activities," paper SECY-78-415 prepared for the Commissioners of the U.S. Nuclear Regulatory Commission, Ju1y 31, 1978. 
15. Marshall, Eliot, "NAS Study on Radiation Takes the Middle Road," Science, Vol. 204, May 18, 1979, pp. 711-714.

16. Becker, F. B., Cancer, Vol. 1, Plenum Press, New York, 1977.

17. Shabecoff, Philip, "Job Threats to Workers' Fertility Emerging as Civil Liberties Issue," New York Times, January 15, 1979, pp. Al, D8.

18. Richards, Bill, "Five Women Say They Were Pressured Into Sterilizations to Keep Chemical Plant Jobs," Los Angeles Times, January 2, 1979, Part I, p. 5.

19. "Study Finds Discrimination Against Radiation Workers," Nuclear News, Vo1. 21, No. 14, November 1978, pp. 162-166. 